\title{
Testicular Volume and Reproductive Status of Wild Callithrix jacchus
}

\author{
Arrilton Araújo • \\ Maria Bernardete Cordeiro de Sousa
}

Received: 24 April 2007 / Accepted: 10 June 2008 /

Published online: 3 September 2008

(C) Springer Science + Business Media, LLC 2008

\begin{abstract}
The social relationship dynamic among callitrichid females is well known. Breeding exclusivity by dominant females involves female-female competition, usually resulting in the inhibition of subordinate reproduction. However, the strategies to maintain the male breeding position are still unclear. Researchers have observed no overt aggression between males, and differences in testosterone levels between dominant and subordinate individuals do not correlate with differences in reproductive success. In Callithrix monogamy is the predominant mating system, and testicular size is compatible with the absence of sperm competition. We analyzed testicular volume during development in 95 individuals at different ages (infant $n=$ 12 , juvenile $n=9$, subadult $n=15$, and adult $n=59$ ). We also investigated if the ratio between testicular volume and body mass correlates with breeding position in the social group. The ratio was significantly higher in breeding males and a positive correlation between body mass and testicular volume is significant only for nonbreeding males. The findings suggest that testicular size varies with male reproductive status in the social group and that the enlargement of testicular volume in breeding common marmoset males seems to be a result of proximate causes and to depend on social and reproductive contexts acting together or separately.
\end{abstract}

Keywords male reproductive strategies · testis/body mass ratio · wild common marmoset

\section{Introduction}

Studies on female sexual strategies have yielded important data on the flexibility of common marmoset mating systems but, for males, few data are available on the mechanisms by which they reach reproductive status and impair the reproduction of

\footnotetext{
A. Araújo $(\varangle) \cdot$ M. B. C. de Sousa

Psychobiology Graduate Program, Department of Physiology,

Universidade Federal do Rio Grande do Norte, 59078-970 Natal-RN, Brazil

e-mail: arrilton@cb.ufrn.br
} 
subordinates. Some researchers have noted the exclusivity of reproduction by adult male Callithrix jacchus (Abbott 1984, 1993; Anzenberger 1985; Araújo 1996; Araújo and Arruda 1995; Digby 1999), but Goldizen (1987, 1989, 1990) suggested that for Saguinus, polyandry is the main mating system. Comparison of behavioral and endocrine profiles of male Callithrix khulii in artificial polyandrous (2 related or familiar males and 1 female) and monogamous groups suggests a nonmonopolizing facultative strategy because males show low overt agonism and differences in behavior and no change in urinary testosterone or cortisol (Schaffner and French 2004). The data suggest low competition between callitrichid males, and according to Huck et al. (2005), who tested the prediction of the challenging hypothesis, no change in testosterone occurs between reproductive and nonreproductive freeranging male Saguinus mystax. They suggested that reproductive competition in the tamarins involves no hormonal mechanism but seems to entail a combination of behavioral mechanisms and sperm competition.

Studies on the relationships between wild (Araújo 1996; Lazaro-Perea et al. 2000) and captive (Araújo and Yamamoto 1994; Baker et al. 1999) common marmoset males also show low agonistic interactions between males. Baker et al. (1999), studying fathers and sons in family groups, investigated if reproductive failure in subordinate males was a consequence of competition, avoidance of mating with relatives, or both. They found no significant difference in plasma testosterone between fathers and sons and when tested together they showed significantly less sexual behavior than when tested alone with an unrelated female. The authors suggest that both competition and incestuous avoidance seem to be involved in the reproductive suppression of sons living in family groups. Abbott (1984) also found no difference between plasma testosterone levels of unrelated dominant and subordinate males. Castro and Sousa (2005) described a significant increase in the basal levels of fecal androgen excretion in adult sons vs. their fathers when mothers were pregnant. Baker et al. (1999) and Castro and Sousa (2005), respectively, suggested that the similar and higher testosterone levels in adult sons might be an adaptation to being aroused by the presence of a probable mate during intergroup encounters in wild conditions, increasing the opportunity for subordinates to copulate. Long-term data from field studies (Arruda et al. 2005; Castro and Araújo 2004; Lazaro-Perea et al. 2000; Lazaro-Perea 2001) have reinforced this theory, because free-ranging nonbreeding common marmosets copulate with females from neighboring groups during or immediately after encounters along home-range borders.

Evidence from our field studies shows that common marmoset groups always have a multimale/multifemale social structure, and in some cases it is difficult to identify the reproductive male. Even so, in general, affiliative and sexual interactions (Albuquerque et al. 2001; Araújo 1996; Digby 1995, 1999; Lazaro-Perea 2001) characterize breeding pairs in free-ranging groups. Thus, because males living within the same social group show low-intensity agonistic interactions, they might use other tactics to maintain reproductive exclusivity with breeding females. Some authors have described mate guarding and sperm competition as part of male callitrichid strategy (Digby 1995, 1999; Huck et al. 2005). For free-ranging common marmosets, mate-guarding behavior is frequently reported around the postpartum period (Albuquerque et al. 2001; Arruda et al. 2005 Digby 1995; Lazaro-Perea 
2001), but according to Harcourt et al. (1981) and Dixson and Anderson (2004), common testicular size in marmosets does not suggest sperm competition, as expected for a primarily monogamous species. Though reproductive males performed different roles within the group, mainly during intergroup encounters (Araújo 1996; Lazaro-Perea 2001; Lazaro-Perea et al. 2000), no information is available on testicular size associated to social rank. Therefore, we aimed to correlate the stages of development and testicular volume in free-ranging common marmosets and to determine if the ratio between testicular volume and mass depends on the reproductive status of males in the social group.

\section{Methods}

\section{Subjects}

We collected data from marked, habituated males living in 15 free-ranging groups at the Floresta Nacional de Nísia Floresta field station (FLONA, of the Instituto Chico Mendes de Biodiversidade) $40 \mathrm{~km}$ from Natal, NE-Brazil. The station covers 170 ha, 70 ha of which is secondary Atlantic forest, 50 ha Tabuleiro vegetation, and 50 ha exotic trees, mainly Eucalyptus.

We captured 12 infants, 9 juveniles, 15 subadults, and 59 adult common marmoset males in manually operated cage-traps, to which we habituated them for $3 \mathrm{~d}$ before the actual trapping. On the day of capture, one of us stalked the subjects until they entered the trap. At that moment, we released the door and caught them. We covered the cage with a black cloth to calm them during transfer to a field station laboratory. Once in the laboratory we anesthetized them with $0.03 \mathrm{mg} / \mathrm{kg}$ of ketamine hydrochloride and weighed and measured them. After anesthesia recovery, never $>1.5 \mathrm{~h}$, we released them at the same location where we trapped them (Araújo et al. 2000). After release, we waited until the subjects rejoined the group, which we followed until they retired to the sleeping site. The next day we followed the group from the moment they left the sleeping site. We trapped all infants and juveniles only when we jointly captured another adult and always released them with an adult from their own group.

A tricolored collar and a tattoo on the inner surface of the forelimb identified individuals weighing $>200 \mathrm{~g}$. We identified individuals weighing $<200 \mathrm{~g}$ via tail trichotomy and dyeing different parts of the body with picric acid. We assigned the individuals to 1 of 4 age classes: infants $(0-5 \mathrm{mo})$, juveniles $(5-10 \mathrm{mo})$, subadults (10-15 mo), and adults (>15 mo) per Yamamoto (1993). We used broad age classes to allow for errors in age estimation.

\section{Body Mass and Testicular Volume Measurement}

We weighed each male immediately after anesthesia. We then placed him in a prone position to measure the length and width of the testis through the scrotum via digital calipers. The observer pressed the scrotal skin taut to reveal the testis. We did not measure scrotal skinfolds. We performed all the measurements identically to ensure consistency. All the males were wild and we released them into their home range. 
We measured both testes in $96 \%$ of the individuals. In $4 \%$ we measured only the right testis; thus, we used only right testicular measures in the testicular volume analyses. Moreover, there was no difference between the volumes of the 2 testes. (Wilcoxon's matched pairs test: $p=0.21$ ). We calculated testicular volume via the formula $0.523 \times L \times W^{2}$ (Abbott and Hearn 1978), wherein $L=$ length and $W=$ width.

We followed 7 of 15 trapped groups once a week to collect behavioral data for other studies for $\geq 1 \mathrm{yr}$ and $\leq 5 \mathrm{yr}$. The behavioral data allowed us to identify the dominant breeding males $(n=14)$, i.e., individuals that copulated or attempted copulation with reproductive females from their social groups for $\geq 1 \mathrm{yr}$ ( $\mathrm{ca}$. 2 conceptions from the reproductive female). We considered the other adult males in the groups to be nonbreeding $(n=28)$. Some nonbreeding males attempted copulation with females from a neighboring group during intergroup encounters (Arruda et al. 2005). We studied the remaining 8 groups for a short period on a more irregular basis and included them only in the analysis of testicular development and aging.

We captured 20 males more than once. In this case, except for the infantile stage, we considered only the measures obtained for the first age class in which the individuals were captured. For those captured twice or more within the same development class, we considered the mean of all measurements. As a result, we had only 1 value for each individual in each age class.

\section{Statistical Analysis}

We calculated the ratio between testicular volume and body mass $\left(V_{\mathrm{t}} / B_{\mathrm{m}}\right)$ for the 4 age stages. To compare testicular volume and body mass among the age classes and seasons in which we captured the males, we used Kruskal-Wallis ANOVA by ranks $(H)$ and Mann-Whitney $U$ test. We compared testicular volume between breeding and nonbreeding males via the Mann-Whitney $U$ test. We calculated the Spearman correlation coefficient $\left(r_{s}\right)$ via testicular volume and body mass measures (Howell 1998). In all analyses, we established $p \leq 0.05$ as significant.

\section{Results}

Testicular volume $\left(H_{1,95}=0.26, p=0.61\right)$ and body mass $\left(H_{1,95}=2.86, p=0.09\right)$ do not differ according to capture season (rainy season: March to August; and dry season: September to February). Figure 1 contains a significant positive correlation between testicular volume and body mass $\left(r_{s}=0.66, p=0.001\right)$, indicating both an increase in testicular volume $\left(H_{3}, 95=40.48 ; p=0.001\right)$ and body mass with advancing age $\left(H_{3,95}=58.47, p=0.001, U\right.$ test, for all comparisons $\left.p \leq 0.04\right)$. Infants, juveniles, and subadults show similar testicular volumes ( $U$ test, $p>0.05$ ) and adults show significantly different testicular volume vs. all age classes ( $U$ test, $p=0.01)$. However, our analysis of relative testicular volumes (ratio between testicular volume/body mass) in the 4 age classes shows that the ratio in the infantile and adult stages is higher than that of juveniles and subadults $\left(H_{3,95}=9.72, p=0.02, U\right.$ test infant $\times$ juvenile and subadult $p=0.05$, adult $\times$ juvenile and subadult $p=0.01$; Fig. 2). 
Fig. 1 Correlation between testicular volume $\left(\mathrm{cm}^{3}\right)$ and body mass $(\mathrm{g})$ in wild common marmosets.

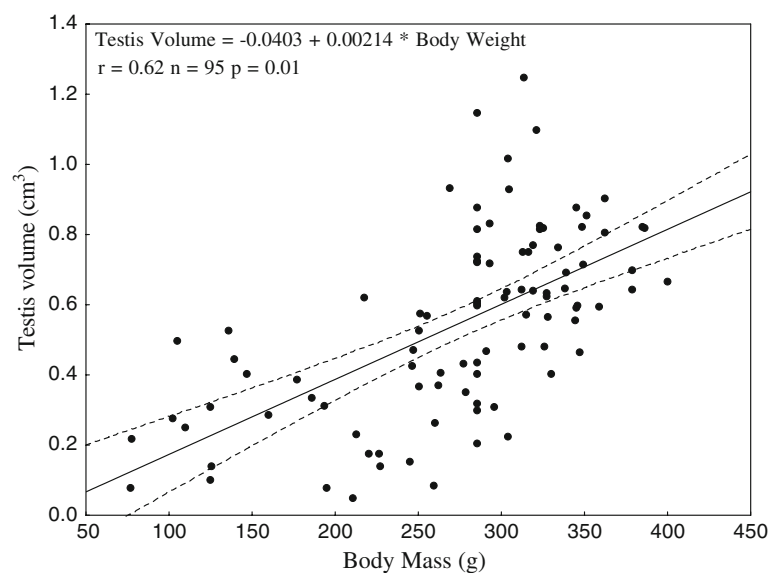

There is a significant difference $(U=85.0, p=0.003)$ in testicular volume between breeding and nonbreeding adult males (Fig. 3), but no difference for body mass $(U=$ 190.0, $p=0.87$; Table I). There is a significant positive correlation between testicular volume and body mass for nonbreeding males $\left(r_{s}=0.59, p=0.009\right)$ but not for breeding males $\left(r_{s}=0.47, p=0.09\right)$, as shown in Fig. 4 .

\section{Discussion}

Body and testicular development in wild common marmosets appears to occur over different age ranges. Using body mass to monitor the physical development of wild common marmosets (Araújo et al. 2000) results in the same profile as that described for captive marmosets (Abbott and Hearn 1978). The body and testicular development curves that we obtained are in accordance with the typical pattern for anthropoid primates, with rapid neonatal growth, a slow juvenile phase, and a second peak of rapid development during adolescence (Plant 1988). Body mass values in the adult subjects were similar to those previously described (captivity: Abbott and Hearn 1978; wild: Araújo et al. 2000) and to those of captives observed for testicular volume (Abbott and Hearn 1978; Dixson 1986). Testicular volume in infants and juveniles is similar but a rapid increase occurred between the juvenile

Fig. 2 Relative testicular volume $\left(\mathrm{cm}^{3}\right)$ (mean $\left.\pm \mathrm{SE}\right)$ at different ages in wild common marmosets. Bars not sharing a same letter are statistically different from each other.

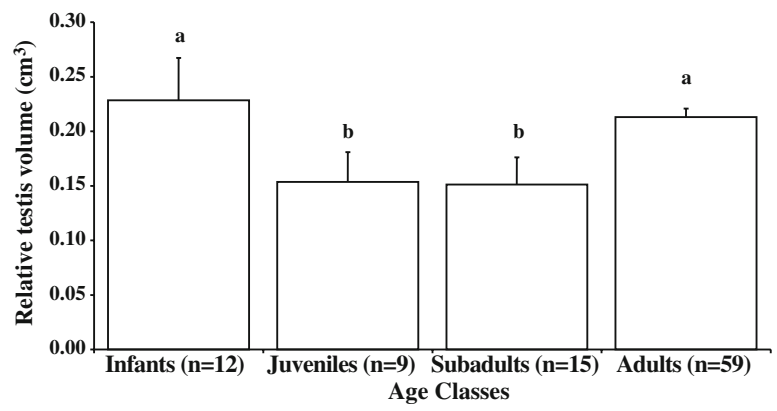


Fig. 3 Testicular volume/body mass ratio (mean $\pm \mathrm{SE})$ in breeding and nonbreeding adult wild common marmosets $(* p=0.01)$.

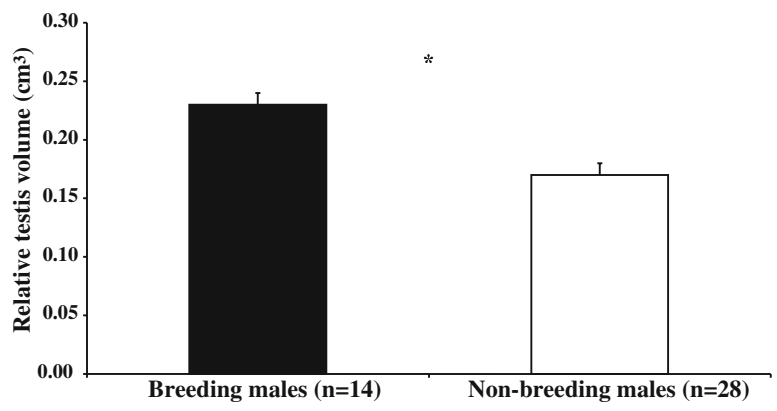

and subadult ages, reaching, as expected, the highest values in adulthood. However, relative testicular volume, i.e., testicular volume/body mass ratio, is comparable in the infantile and adult stages, indicating relatively large testicular volume during infancy. According to Luetjens et al. (2005) and Li et al. (2005), in common marmosets, after birth the number of testicular germ cells starts to increase from 56 wk until 5 mo. The number of both Leydig and Sertoli cells associated with testosterone production and spermatogenetic process, respectively, also increases during the infantile stage, decreasing from the 6th to 8th mo ( $\mathrm{Li}$ et al. 2005). Therefore, the increase in testicular volume in the infantile stage is associated with testicular cell proliferation. Increased testicular volume in adults is related to increased spermatogenetic activity, testosterone production, and spermatozoid maturation ( $\mathrm{Li}$ et al. 2005). The relatively high testicular volume in the infantile stage is also coincident with the peak of testosterone production from birth until the 110th day in male common marmosets (Dixson 1986). It is important to note that we measured the testis when the individuals were 3-5 mo old because the fully descended testes in callitrichids occurs around then (Saguinus oedipus oedipus: 8 wk, Ginther et al. 2002; Callithrix jacchus: 50-70 d, Abbott and Hearn 1978). Indeed, Abbott and Hearn (1978) found a rapid increase in testicular growth from 9 to 24 mo of age. Ginther et al. (2002) recorded the same increase for Saguinus oedipus oedipus. Though we did not detect the same growth pattern as that of captives in the subadult stage, we noted large variability of volume, which might be due to more regular data collection under captive conditions.

We also found that testicular volume in adult common marmosets varies significantly according to their social status within the group. Our laboratory records and those of other researchers showing that callitrichids do not exhibit linear hierarchy (Araújo 1996; Rylands 1996; Stevenson and Rylands 1988; Sussman and

Table I Testicular volume and body mass according to the reproductive status of wild common marmoset (Callithrix jacchus) males at FLONA Nisia Floresta, Brazil

\begin{tabular}{llllllll}
\hline Male status & \multicolumn{5}{l}{ Testicular volume $\left(\mathrm{cm}^{3}\right)$} & & \multicolumn{3}{l}{ Body mass $(\mathrm{g})$} \\
\cline { 2 - 3 } & Mean & Standard error & Range & & Mean & Standard error & Range \\
\hline Breeding $(n=14)$ & 0.75 & 0.03 & $0.59-0.93$ & & 323.20 & 6.36 & $250.30-351.00$ \\
Nonbreeding $(n=28)$ & 0.56 & 0.04 & $0.17-0.88$ & & 318.72 & 8.16 & $218.00-392.30$ \\
\hline
\end{tabular}


Fig. 4 Testicular volume $\left(\mathrm{cm}^{3}\right)$ and body mass $(\mathrm{g})$ correlation in breeding (a) and nonbreeding (b) wild common marmosets.

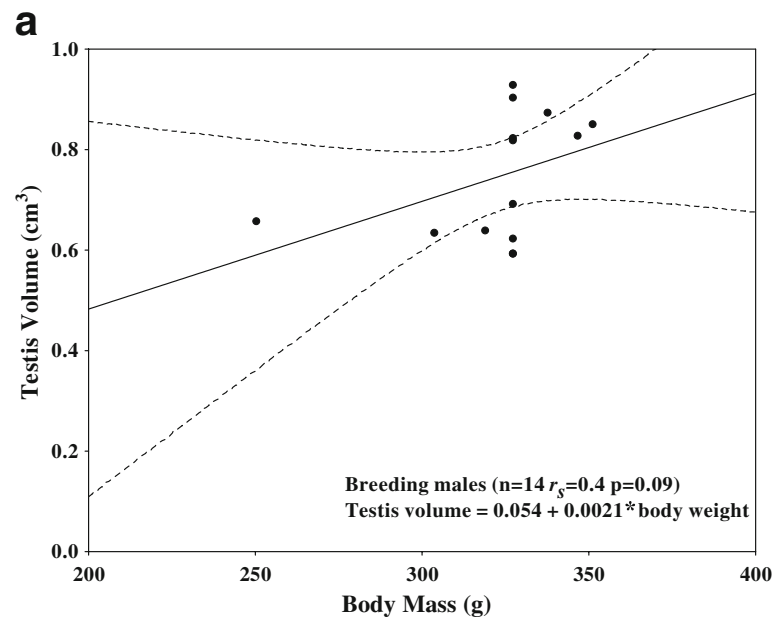

b

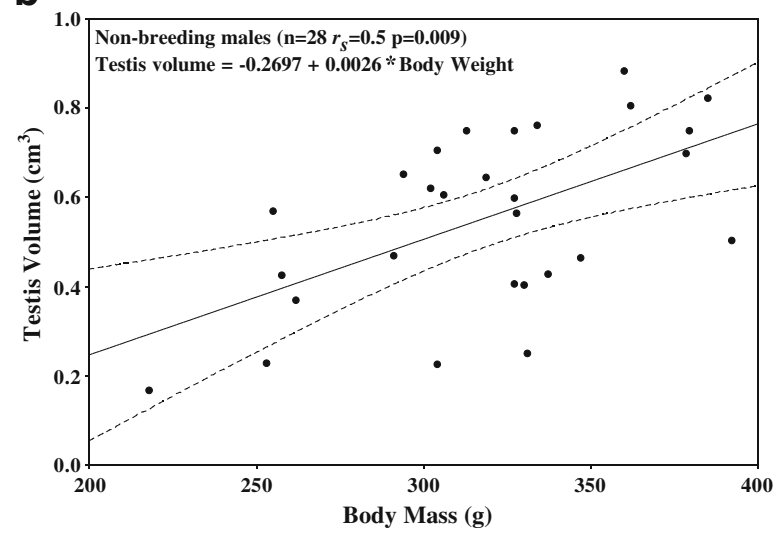

Garber 1987; cf. Röthe 1975; Röthe and Darms 1993), suggest that the increase might be related to the role of reproductive males in the social group. Dominant males assume a leadership position during intergroup encounters and, consequently, are more exposed to conflict and aggressive interactions with other individuals. According to Ross et al. (2004), testosterone increase in Callithrix kuhlii is proportional to the intensity of aggression during male-male conflicts, and males that are more aggressive produce significantly more testosterone than nonaggressive individuals do. Testosterone changes are also related to parental activities (Callithrix jacchus: Dixson and George 1982; Callithrix kuhlii Nunes et al. 2000) and postpartum estrus (Barbosa 2003). Testosterone concentration in Callithrix kuhlii also changes with parental care experience. Nunes et al. (2000) showed that, even in fathers that spend the same amount of effort in caring for infants, testosterone is higher when they are caring for the first litter than when caring for the second.

We demonstrate that testicular volume in adult common marmosets does not depend on body mass but instead on reproductive status. In all free-ranging groups researchers have studied to date (Araújo 1996; Arruda et al. 2005; Digby 1995; Lazaro-Perea et al. 2000), the researchers recorded no copulation between 
subordinate males and breeding females. However, Arruda et al. (2005) noted that subordinate females copulated with extragroup males. The 4 groups Arruda et al. (2005) observed are included in our study, as are the neighboring groups containing the extragroup males. The extragroup copulations occurred infrequently in comparison to reproducing pair copulations.

Nievergelt et al. (2000) and Faulkes et al. (2003, in press) used microsatellite genotyping to investigate 5 social groups (also included in our study). The results of the studies suggest that genetic structure may often be more heterogeneous and the relatedness between adult males from the same group is significantly lower. However, given that most of our focal males do not belong to the sample of the aforementioned genetic studies, we cannot use the finding as an argument for the lower testicular volume of nonbreeding males. The breeding males and females are from different lineages resulting from migratory movements between the groups (Faulkes et al. 2003, in press; Nievergelt et al. 2000; Sousa et al. 2005, in press), which causes reproducing males to mate more regularly, whereas the nonreproducing males mate whenever possible with females from neighboring groups or when they assume a reproductive role (Arruda et al. 2005; Yamamoto et al. in press).

Thus, the increased testicular volume of breeding males seems to be related to challenging situations that dominant males face under natural conditions, such as resource defense (territory, mate, infants) and reproduction itself (mating, sperm production). Therefore, the reproductive strategies of common marmoset breeding males might be a combination of behavioral (mate guarding) and physiological (frequent copulation) mechanisms influencing their reproductive output.

Acknowledgments We thank the Chico Mendes Institute for Conservation and Biodiversity (ICM Biod.-RN) for permission (no. 12547-1) to work at the Floresta Nacional de Nisia Floresta, and the Brazilian Foundation for the Improvement of Higher Level Graduates (CAPES), and the Brazilian Science Council (CNPq) for grants to Arrilton Araújo (CAPES grant 864/91-11 and CNPq grants 523963/96-3 and 464103/00-2) and Maria Bernardete C. Sousa (CNPq grants 305216/2003-1 and 308280/2006-7). We also thank the Universidade Federal do Rio Grande do Norte (Brazil) for their generous support.

\section{References}

Abbott, D. H. (1984). Behavioural and physiological suppression of fertility in subordinate marmoset monkeys. American Journal of Primatology, 6, 169-186. doi:10.1002/ajp.1350060305.

Abbott, D. H. (1993). Social conflict and reproductive suppression in marmoset and tamarin monkeys. In W. A. Mason, \& S. P. Mendoza (Eds.), Primate social conflict (pp. 331-372). Albany, NY: State University of New York.

Abbott, D. H., \& Hearn, J. (1978). Physical, hormonal and behavioural aspects of sexual development in the marmoset monkey, Callithrix jacchus. Journal of Reproduction and Fertility, 53, 155-166. doi:10.1530/jrf.0.0530155.

Albuquerque, A. C. S. R., Sousa, M. B. C., Santos, H. M., \& Ziegler, T. E. (2001). Behavioral and hormonal analysis of social relationships between oldest females in a wild monogamous group of common marmosets (Callithrix jacchus). International Journal of Primatology, 22, 631-645. doi:10.1023/A:1010741702831.

Anzenberger, G. (1985). How stranger encounters of common marmosets (Callithrix jacchus jacchus) are influenced by family members: The quality of behavior. Folia Primatologica, 45, 204-224.

Araújo, A. (1996). Influence des facteurs écologiques, comportementaux et démographiques sur la dispersion de Callithrix jacchus. Ph.D. thesis, Paris-Nord University, France, 209 pp. 
Arruda, M. F., Araújo, A., Sousa, M. B. C., Albuquerque, F. S., Albuquerque, A. C. S. R., \& Yamamoto, M. E. (2005). Two-breeding females within free-living groups may not always indicate polygyny: Alternative subordinate female strategies in common marmosets (Callithrix jacchus). Folia Primatologica, 76, 10-20. doi:10.1159/000082451.

Araújo, A., \& Arruda, M. F. (1995). Dispersion in Callithrix jacchus (Callitrichidae, Primates) at Nisia Floresta, North-East Brazil. Folia Primatologica, 64, 73.

Araújo, A., Arruda, M. F., Alencar, A. I., Albuquerque, F., Nascimento, M. C., \& Yamamoto, M. E. (2000). Body weight of wild and captive common marmosets (Callithrix jacchus). International Journal of Primatology, 21, 317-324. doi:10.1023/A:1005433722475.

Araújo, A., \& Yamamoto, M. E. (1994). Reação à intrusos da mesma espécie em Callithrix jacchus: Influência do status social. In M. E. Yamamoto, \& M. B. C. Sousa (Eds.), A Primatologia no Brasil (vol. 4, (pp. 15-34)). Natal: SBPr/Editora Universitária.

Baker, J. V., Abbott, D. H., \& Saltzman, W. (1999). Social determinants of reproductive failure in male common marmosets housed with their natal family. Animal Behaviour, 58, 501-513. doi:10.1006/ anbe. 1999.1200 .

Barbosa, M. F. P. P. (2003). Níveis de esteróides e comportamentos sócio-sexuais do par reprodutor de Callithrix jacchus durante os períodos de gestação e pós-parto. Ph.D. thesis, Universidade Federal do Rio Grande do Norte: Natal, 102 pp.

Castro, C. S., \& Araújo, A. (2004). Interação agonísticas entre grupos de sagüis (Callithrix jacchus): defesa de recursos ou localização de parceiros sexuais extra-grupo? In S. Mendes, \& A. Chiarello (Eds.), A primatologia no Brasil (vol. 8, (pp. 201-212)). Vitoria: SBPr/Editora da Universidade Federal do Espírito Santo.

Castro, D. C., \& Sousa, M. B. C. (2005). Androgen levels in common marmoset (Callithrix jacchus) males living in captive family groups. Brazilian Journal of Medical and Biological Research, 38, 6572.

Digby, L. J. (1995). Social organization in a wild population of Callithrix jacchus: II. Intragroup social behavior. Primates, 36, 361-375. doi:10.1007/BF02382859.

Digby, L. J. (1999). Sexual behavior and extra-group copulations in a wild population of common marmosets (Callithrix jacchus). International Journal of Primatology, 15, 389-397. doi:10.1007/ BF02696100.

Dixson, A. F. (1986). Plasma testosterone concentration during postnatal development in the male common marmoset. Folia Primatologica, 47, 166-170.

Dixson, A. F., \& Anderson, M. J. (2004). Sexual behavior, reproductive physiology and sperm competition in male mammals. Physiology \& Behavior, 83, 361-371.

Dixson, A. F., \& George, L. (1982). Prolactin and parental behavior in a male new-world primate. Nature, 299, 551-553. doi:10.1038/299551a0.

Faulkes, C. G., Arruda, M. F., \& Monteiro da Cruz, M. A. O. (2003). Matrilineal genetic structure within and among populations of the cooperatively breeding common marmoset, Callithrix jacchus. Molecular Ecology, 12, 1101-1108. doi:10.1046/j.1365-294X.2003.01809.x.

Faulkes, C. G., Arruda, M. F., \& Monteiro da Cruz, M. A. O. (in press). Genetic structure within and among populations of the common marmoset, Callithrix jacchus: Implications for cooperative breeding. In S. M. Ford, L. M. Porter, \& L. C. Davis (Eds.), The smallest anthropoids: The marmoset/ callimico radiation (736 pp). New York: Springer.

Ginther, A. J., Carlson, A. A., Ziegler, T. E., \& Snowdon, C. T. (2002). Neonatal and pubertal development in males of a cooperatively breeding primate, the cotton-top tamarin (Saguinus oedipus oedipus). Biology of Reproduction, 66, 282-290. doi:10.1095/biolreprod66.2.282.

Goldizen, A. W. (1987). Facultative polyandry and the role of infant-carrying in wild saddle-back tamarins (Saguinus fuscicollis). Behavioral Ecology and Sociobiology, 20, 99-109. doi:10.1007/BF00572631.

Goldizen, A. W. (1989). Social relationship in a cooperativelly polyandrous group of tamarins (Saguinus fuscicollis). Behavioral Ecology and Sociobiology, 24, 79-89. doi:10.1007/BF00299639.

Goldizen, A. W. (1990). A comparative perspective on the evolution of tamarin and marmoset social systems. International Journal of Primatology, 11, 63-83. doi:10.1007/BF02193696.

Harcourt, A. H., Harvey, P. H., Larson, S. G., \& Short, R. V. (1981). Testis weight, body weight and breeding system in primates. Nature, 293, 55-57. doi:10.1038/293055a0.

Howell, D. C. (1998). Statistical methods for psychology (3rd ed.). Belmont: Duxbury Press.

Huck, M., Eckhard, P., Heymann, W., \& Heistermann, M. (2005). Characterization and social correlates of fecal testosterone and cortisol excretion in wild male Saguinus mystax. International Journal of Primatology, 26, 159-179. doi:10.1007/s10764-005-0728-8. 
Lazaro-Perea, C. (2001). Intergroup interactions in wild common marmosets, Callithrix jacchus: Territorial defense and assessment of neighbors. Animal Behaviour, 62, 11-21. doi:10.1006/ anbe.2000.1726.

Lazaro-Perea, C., Castro, C. S. S., Harrison, R., Araújo, A., Arruda, M. F., \& Snowdon, C. T. (2000). Behavioral and demographic changes following the loss of the breeding female in cooperatively breeding marmoset. Behavioral Ecology and Sociobiology, 48, 137-146. doi:10.1007/ s002650000215.

Li, H.-L., Donald, J. M., \& Golub, M. S. (2005). Review on testicular development, structure, function and regulation in common marmoset. Birth Defects Research, 74, 450-469. doi:10.1002/bdrb.20057.

Luetjens, C. J., Wienbauer, G. F., \& Wistuba, J. (2005). Primate spermatogenesis: New insights into comparative testicular organisation, spermatogenic efficiency and endocrine control. Biological Reviews of the Cambridge Philosophical Society, 80, 475-488. doi:10.1017/S1464793105006755.

Nievergelt, C. M., Digby, L. J., Ramakrishnan, U., \& Woodruff, D. S. (2000). Genetic analysis of group composition and breeding system in a wild common marmoset (Callithrix jacchus) population. International Journal of Primatology, 21, 1-20. doi:10.1023/A:1005411227810.

Nunes, S., Fite, J. E., \& French, J. A. (2000). Variation in steroid hormones associated with infant care behaviour and experience in male marmosets (Callithrix kuhlii). Animal Behaviour, 60, 857-865. doi:10.1006/anbe.2000.1524.

Plant, T. M. (1988). Puberty in primates. In E. Knobil, \& J. Neil (Eds.), The physiology of reproduction (pp. 1763-1788). New York: Raven Press.

Ross, C. N., French, J. A., \& Kimberly, J. P. (2004). Intensity of aggressive interactions modulates testosterone in male marmosets. Physiology \& Behavior, 83, 437-445. doi:10.1016/j.physbeh. 2004.08.036.

Röthe, H. (1975). Some aspects of sexuality and reproduction in groups of captive marmosets (Callithrix jacchus). Zeitschrift fur Tierpsychologie, 37, 255-273.

Röthe, H., \& Darms, K. (1993). The social organization of marmosets: A critical evaluation of recent concepts. In A. B. Rylands (Ed.), Marmosets and tamarins. Systematics, behaviour, and ecology (pp. 176-199). Oxford: Oxford University Press.

Rylands, A. B. (1996). Habitat and the evolution of social and reproductive behavior in Callitrichidae. American Journal of Primatology, 38, 5-18. doi:10.1002/(SICI)1098-2345(1996)38:1<5::AIDAJP2>3.0.CO;2-2.

Schaffner, C. M., \& French, J. A. (2004). Behavioral and endocrine responses in male marmosets to the establishment of multimale breeding groups: Evidence for non-monopolizing facultative polyandry. International Journal of Primatology, 25, 709-732. doi:10.1023/B:IJOP.0000023582.34854.43.

Sousa, M. B. C., Albuquerque, A. C. S. R., Albuquerque, F. S., Araújo, A., Yamamoto, M. E., \& Arruda, M. F. (2005). Behavioral strategies and hormonal profile of dominant and subordinate common marmoset (Callithrix jacchus) females in wild monogamous groups. American Journal of Primatology, 67, 37-50. doi:10.1002/ajp.20168.

Sousa, M. B. C., Araújo, A., Yamamoto, M. E., Albuquerque, A. C., Albuquerque, F. S., \& Arruda, M. F. (in press). Emigration as a reproductive strategy of the common marmosets (Callithrix jacchus). In L. C. Davis, S. M. Ford, \& L. M. Porter (Eds.), The smallest anthropoids: The marmoset/callimico radiation (736 pp). New York: Springer.

Stevenson, M. F., \& Rylands, A. B. (1988). The marmosets, genus Callithrix. In R. A. Mittermeier, A. B. Rylands, A. F. Coimbra-Filho, \& G. A. B. Fonseca (Eds.), Ecology and behavior of neotropical primates (vol. 2, (pp. 131-222)). Contagem: Littera Maciel.

Sussman, R. W., \& Garber, P. A. (1987). A new interpretation of the social organisation and mating system of the Callitrichidae. International Journal of Primatology, 8, 73-92. doi:10.1007/ BF02737114.

Yamamoto, M. E. (1993). From dependence to sexual maturity: The behavioural ontogeny of Callitrichidae. In A. B. Rylands (Ed.),Marmosets and tamarins. Systematics, behaviour e ecology (pp. 235-254). Oxford: Oxford University Press.

Yamamoto, M. E., Arruda, M. F., Alencar, A. I., Sousa, M. B. C., \& Araújo, A. (in press). Mating systems and female-female competition in the common marmosets, Callithrix jacchus. In L. C. Davis, S. M. Ford, \& L. M. Porter (Eds.), The smallest anthropoids: The marmoset/callimico radiation (736 pp). New York: Springer. 